\title{
FLOW FEATURES OF THERMOPHORETIC MHD VISCOUS FLUID FLOW PAST A CONVERGING CHANNEL WITH HEAT SOURCE AND CHEMICAL REACTION
}

\author{
B.K. KALITA* and R. CHOUDHURY \\ Department of Mathematics, Gauhati University, Guwahati, INDIA \\ E-mail: kumar90bhrigu@gmail.com
}

\begin{abstract}
A boundary layer flow of an electrically conducting viscous fluid past a converging channel in the presence of thermophoresis, heat source, chemical reaction, viscous dissipation and simultaneous heat and mass transfer characteristics is studied in the paper. An external magnetic field of uniform strength is applied transversely to the channel. The similarity solution has been used to transform the partial differential equations that represent the problem into a boundary value problem of coupled ordinary differential equations, which in turn are solved numerically using MATLAB's built in solver bvp4c. Numerical computations are carried out to solve the problem and graphical illustrations are made to get the physical insight of the same. The convergent channel flow problem of an incompressible electrically conducting viscous fluid in the presence of a magnetic field has a wide range of applicability in different areas of engineering, specially in industrial metal casting and control of molten metal flow.
\end{abstract}

Key words: MHD, viscous fluid, heat source, thermophoresis, Nusselt number, skin friction.

\section{Introduction}

The application of incompressible viscous fluid flow through a convergent or divergent channel is most relevant in various areas such as aerospace, biomechanical, chemical, civil, environmental and mechanical engineering as well as in understanding rivers and canals. Jeffery [1] and Hamel [2] have worked out the mathematical formulations of the problem of convergent channel flow in 1915 and 1916, respectively. Navier-Stokes equations, when simplified, in the particular case of two-dimensional flow through a channel with inclined walls modifies into Jeffery-Hamel problem [3-5]. Jeffery-Hamel flows have been comprehensively studied by a number of authors and discussed in various textbooks[6-9]. Magnetohydrodynamic flow of a viscous fluid through a convergent or divergent channel has been scrutinized by authors, viz. Asadullah et al. [10] and Hosseini et al.[11].

The study of an electrically conducting viscous fluid that flows through convergent or divergent channels when an external magnetic field is applied is not only captivating theoretically but also appealing in mathematical modeling of numerous industrial and biological systems. An application of the theory is observed in the field of industrial metal casting and the control of molten metal flows. The motion of liquid metals or alloys in the cooling systems of advanced nuclear reactors is another area in which the theoretical study of this topic can be applied. Different applications and aspects of magnetohydrodynamic flow have been discussed by Nijsing and Eifler [12], Bansal [13], Moreau [14], Abel et al. [15], etc. The effect of a transverse magnetic field on an electrically conductiong fluid in channels has been studied by Linga Raju $e t$ al.[16]. The influence of chemical reaction on a magnetohydrodynamic flow in different flow configurations has been examined by a few authors, viz. Chandrakala [17], Muthucumaraswamy and Geetha [18], Zigta [19], Fenuga et al. [20] and Vijayalakshmi and Selvajayanthi [21].

\footnotetext{
${ }^{*}$ To whom correspondence should be addressed
} 
The phenomenon in which minuscule particles suspended in a non-isothermal fluid acquire a velocity relative to the fluid in the direction of diminishing temperature is termed thermophoresis. Such type of phenomenon is applicable in drug discovery process, aerosol reactors, heat exchange fouling etc. The effect of thermophoresis on a flow over a stretching sheet has been investigated by Srinivasacharya and Jagadeeshwar [22]. Numeruos authors, viz. Selim et al. [23], Postelnicu [24], Bakier and Gorla [25], Noor et al. [26], Kundu et al. [27], Zueco et al. [28] etc. have explored the impact of thermophoresis on fluid flows of different nature and under various physical configurations.

The present study is devoted to examine significant features of a magnetohydrodynamic viscous incompressible fluid flow through a convergent channel in the presence of thermophoresis, heat source and chemical reaction.

\section{Mathematical formulation}

We consider a steady two-dimensional incompressible viscous fluid flow past a converging channel under the influence of a magnetic field of uniform strength $B(x)$ in the presence of thermophoresis, heat source and first order chemical reaction. The fluid flow is assumed to be in the direction of the $\mathrm{x}$ - axis along the wall of the converging channel and the $y$ - axis is normal to it. The magnetic field acts in the transverse direction of the channel and with the assumption of a small magnetic Reynolds number we ensure that the induced magnetic field is of negligible order in comparison with the applied magnetic field.

Under the above assumptions, the governing equations of motion are:

$$
\begin{aligned}
& \frac{\partial u}{\partial x}+\frac{\partial v}{\partial y}=0 \\
& u \frac{\partial u}{\partial x}+v \frac{\partial u}{\partial y}=U \frac{d U}{d x}+v \frac{\partial^{2} u}{\partial y^{2}}+\frac{\sigma B^{2}}{\rho}(U-u)+g \beta\left(T-T_{\infty}\right)+g \beta^{*}\left(C-C_{\infty}\right), \\
& u \frac{\partial T}{\partial x}+v \frac{\partial T}{\partial y}=\frac{\kappa}{\rho C_{p}} \frac{\partial^{2} T}{\partial y^{2}}+\frac{v}{C_{p}}\left(\frac{\partial u}{\partial y}\right)^{2}+\frac{Q}{\rho C_{p}}\left(T-T_{\infty}\right), \\
& u \frac{\partial C}{\partial x}+v \frac{\partial C}{\partial y}=D \frac{\partial^{2} C}{\partial y^{2}}-K_{C}\left(C-C_{\infty}\right)-\frac{\partial}{\partial y}\left\{V_{t}\left(C-C_{\infty}\right)\right\} .
\end{aligned}
$$

The boundary conditions are given by

$$
\begin{aligned}
& y=0 ; \quad u=0, \quad v=0, \quad T=T_{w}, \quad C=C_{w}, \\
& y \rightarrow \infty ; \quad u \rightarrow U(x), \quad T \rightarrow T_{\infty}, \quad C \rightarrow C_{\infty}
\end{aligned}
$$

where $u, v$ are velocity components along the $x$ and $y$ axes respectively, $U(x)$ is the velocity of potential flow, $\rho$ is the fluid density, $\sigma$ is electric conductivity, $C_{p}$ is the specific heat, $\kappa$ is the thermal conductivity, $T$ and $C$ are dimensional species temperature and concentration respectively, $D$ is the coefficient of chemical molecular diffusivity, $K_{C}$ is the rate of chemical reaction, $Q$ is the heat generation coefficient, $v$ is the kinematic viscosity, $V_{t}\left(=-\frac{K_{t} \vee}{T_{r}} \frac{\partial T}{\partial y}\right)$ is the thermophoretic velocity with $K_{t}$ and $T_{r}$ being the 
thermophoretic coefficient and reference temperature respectively, $T_{w}, T_{\infty}$ are temperatures and $C_{w}, C_{\infty}$ are concentrations at the channel wall and the free stream, respectively.

Following Schlichting (1968), we consider $U(x)=-\frac{a}{x}$ where $a>0$ is the strength of the sink placed at the origin, $B(x)=\frac{B_{0}}{x}$ where $B_{0}$ is constant, dimensionless variable $\eta=y \sqrt{-\frac{U(x)}{x v}}=\frac{y}{x} \sqrt{\frac{a}{v}}$ and stream function $\psi(x, y)=-\sqrt{v a} f(\eta)$ such that $u=\frac{\partial \psi}{\partial y}$ and $v=-\frac{\partial \psi}{\partial x}$ which satisfies Eq.(2.1).

We bring forth the following non-dimensional variables and parameters

$$
\begin{aligned}
& \theta=\frac{T-T_{\infty}}{T_{w}-T_{\infty}}, \quad \varphi=\frac{C-C_{\infty}}{C_{w}-C_{\infty}}, \\
& G_{r}=\frac{g \beta\left(T_{w}-T_{\infty}\right) x^{3}}{a^{2}}, \quad G_{m}=\frac{g \beta^{*}\left(C_{w}-C_{\infty}\right) x^{3}}{a^{2}}, \\
& M=\frac{\sigma B_{0}^{2}}{\rho a}, \quad P_{r}=\frac{\mu C_{p}}{\kappa}, \quad S=\frac{Q x}{\rho C_{p} U}, \quad \gamma=\frac{K_{C} x}{U}, \\
& E=\frac{U^{2}}{C_{p}\left(T_{w}-T_{\infty}\right)}, \quad \tau=-\frac{K_{t}\left(T_{w}-T_{\infty}\right)}{T_{r}}, \quad S_{C}=\frac{\nu}{D} .
\end{aligned}
$$

The modified forms of Eqs (2.2)-(2.4) are:

$$
\begin{aligned}
& f^{\prime \prime \prime}+\left(f^{\prime}\right)^{2}+M f^{\prime}=(M+1)-G_{r} \theta-G_{m} \varphi, \\
& \theta^{\prime \prime}+P_{r} E\left(f^{\prime \prime}\right)^{2}-P_{r} S \theta=0, \\
& \varphi^{\prime \prime}+S_{C} \gamma \varphi-S_{C} \tau\left(\varphi \theta^{\prime \prime}+\varphi^{\prime} \theta^{\prime}\right)=0 .
\end{aligned}
$$

The corresponding boundary conditions are:

$$
\begin{aligned}
& \eta=0 ; \quad f^{\prime}=0, \quad \theta=1, \quad \varphi=1, \\
& \eta \rightarrow \infty ; \quad f^{\prime} \rightarrow 1, \quad \theta \rightarrow 0, \quad \varphi \rightarrow 0 .
\end{aligned}
$$

\section{Method of solution}

Equations (2.8)-(2.10) under the boundary conditions (2.11) and (2.12) are solved numerically using MATLAB's built in solver bvp4c. The non-dimensional velocity, temperature, concentration, skin friction, Nusselt number and Sherwood number are obtained in graphical forms. 


\section{Results and discussion}

The features of boundary layer flow of an electrically conducting magnetohydrodynamic viscous fluid past a converging channel in the presence of thermophoresis, heat source, viscous dissipation, chemical reaction and simultaneous heat and mass transfer have been analyzed. The relevant flow characteristics are illustrated graphically in Figs 1-32. In this problem, we examine the effect of salient non-dimensional parameters involved in the study. The solution is obtained for parameters with values $P_{r}=2.5, M=2, G_{r}=5, G_{m}=5, S=3, E=0.05, S_{c}=0.5, \gamma=1, \tau=1.5$ unless otherwise stated.

The variations of the fluid velocity $u$ against the distance y are exhibited in the Figs 1-7 to illustrate the effects of different dimensionless constants on the velocity field in the presence of other flow parameters involved in the problem. It is noticed that the fluid velocity steps up near the plate and converges to the stream velocity as one moves away from the plate. Figure 1 illustrates that the increase in the Prandtl number causes a fall in the fluid velocity. The ratio of the buoyancy force to the viscous force characterizes the Grashof number for heat transfer $\left(G_{r}\right)$ which is very useful in many technological applications. It is noticed from Fig.2 that the rising value of $G_{r}$ enhances the speed of the fluid velocity. Figure 3 displays the fluid velocity for various values of the magnetic parameter $M$. It is observed that with the increase of $M$, the fluid velocity decreases. This is because the transverse magnetic field in action gives rise to a resistive force called the Lorentz force which has a tendency to retard the velocity of the flow. Figure 4 shows the effect of $G_{m}$ on the fluid flow. With the increase of $G_{m}$ the flow velocity increases. The combined effect of momentum and mass diffusion characterizes the Schmidt number. Figure 5 reveals that with the rise of the Schmidt number $S_{c}$ the fluid velocity exhibits a decelerating trend. Figure 6 demonstrates the effect of the chemical reaction parameter $\gamma$ on the fluid velocity. It is noticed that as the chemical reaction parameter goes up, the velocity increases but there is not much of significant difference between two adjacent velocity graphs for most part along the y-axis. This can be summed up by stating that chemical reaction of order one has a comparatively meager effect on the fluid velocity than other flow parameters. Figure 7 brings out the effect of the thermophoretic parameter on the fluid velocity. It is observed that the fluid velocity gets diminished with the increase of the thermophoretic parameter.

The variations of the temperature $\theta$ against distance y are displayed in Figs 8-10 to explain the effect of the Prandtl number, Eckert number and heat source parameter on the flow temperature in the presence of different fixed flow parameters. Figure 8 illustrates that with the rise of the Prandtl number the temperature of the flow field decreases. It is also observed that for very small values of the Prandtl number, temperature decreases almost linearly as one moves away from the plate. However, for comparatively larger values of the Prandtl number the temperature profile diminishes steeply near the plate and then decreases asymptotically as one moves to infinity. Figure 9 exhibits that a growth of the Eckert number causes a rise in the flow temperature, but the difference in temperature is not much significant. Figure 10 demonstrates that with the rise of the heat source parameter the flow temperature gets reduced.

Figures 11-15 reveal that the concentration profile diminishes sharply near the plate and then proceeds uniformly away from the plate. The concentration profile accelerates with the enhancement of numerical values of the chemical reaction parameter but decelerates with the rise of the heat source parameter, Prandtl number, Schmidt number and thermophoretic parameter.

Figures 16-21 illustrate the effects of different flow parameters on the skin friction of the fluid under consideration. The skin friction declines with the increasing value of the Prandtl number, magnetic parameter, heat source parameter, Schmidt number and thermophoretic parameter but increases with the increase of the chemical reaction parameter. Figures 22-27 exhibit the influence of flow parameters on the Nusselt number. From these figures, it is observed that the increase in the Prandtl number, magnetic parameter, Schmidt number, heat source parameter and thermophoretic parameter enforces a declination in the heat flux of the flow but the chemical reaction parameter increases the rate of heat flux. The effect of different flow parameters on the Sherwood number is shown in Figs 28-32. It is observed that with the increase in the Prandtl number, heat source parameter, Schmidt number and thermophoretic parameter, the 
Sherwood number gets diminished but a rise in the chemical reaction parameter exhibits an opposite scenario.

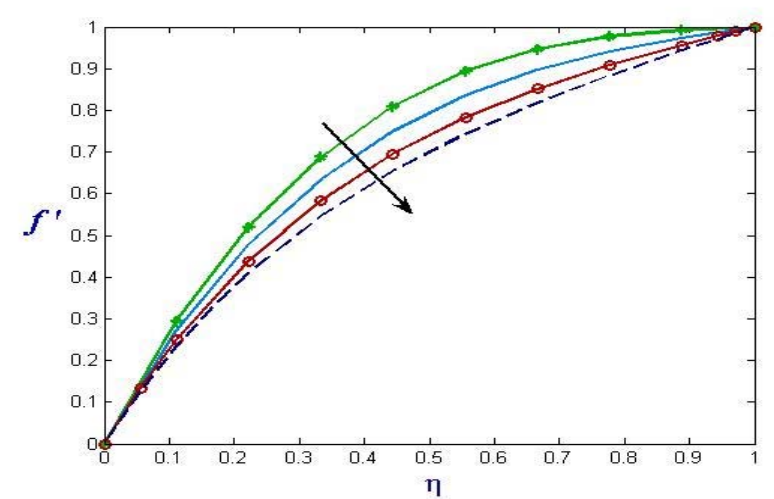

Fig.1. Velocity for different values of $P_{r}=1.7,2.5,3.5,4.5$.

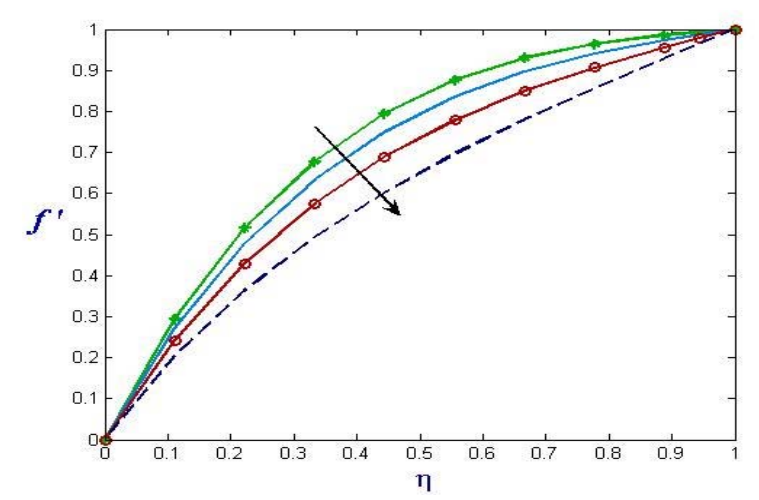

Fig.3. Velocity for different values of $M=1,2,3,4$.

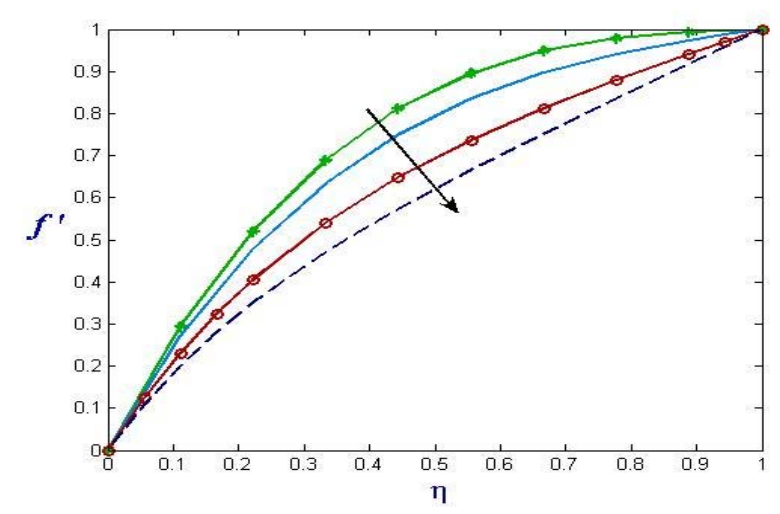

Fig.5. Velocity for different values of $S_{C}=0.25,0.5,1.0,1.5$.

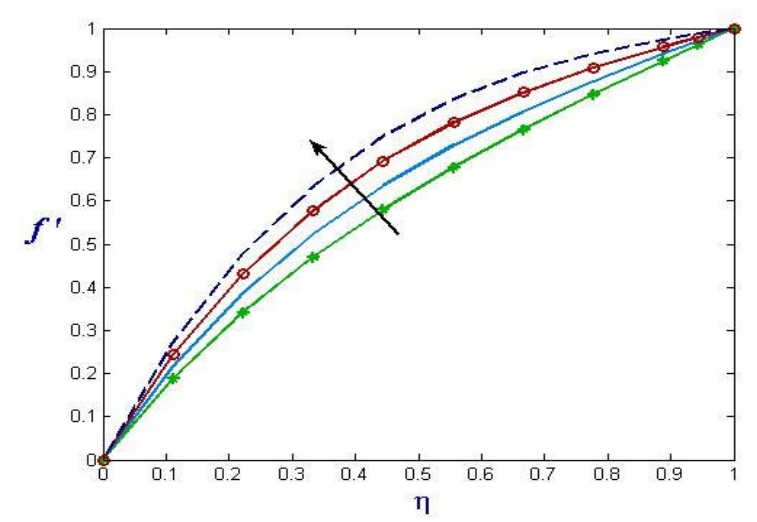

Fig.2. Velocity for different values of $G_{r}=2,3,4,5$.

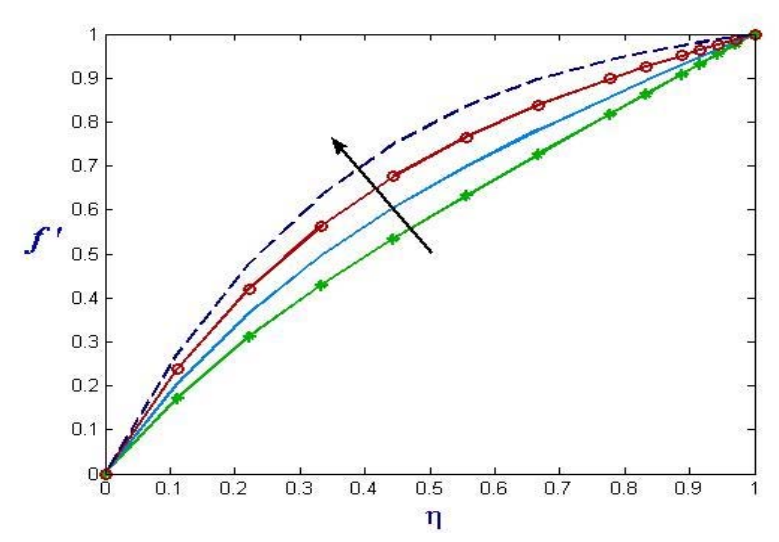

Fig.4. Velocity for different values of $G_{m}=2,3,4,5$.

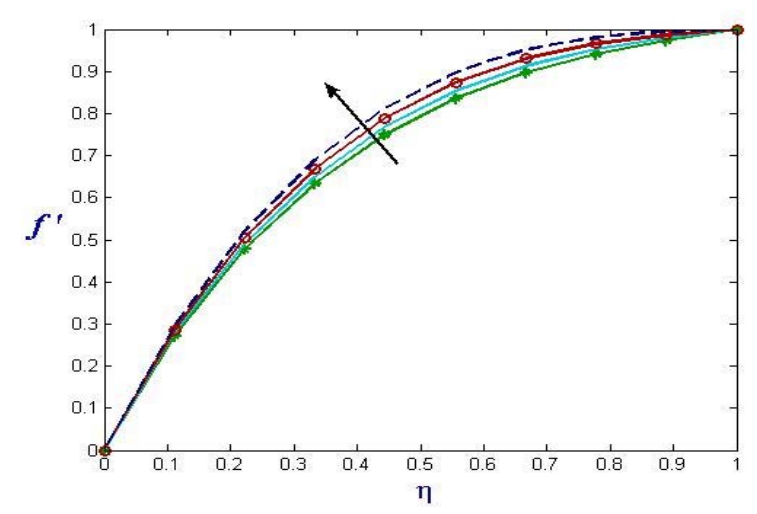

Fig.6. Velocity for different values of $\gamma=1,2,3,4$. 


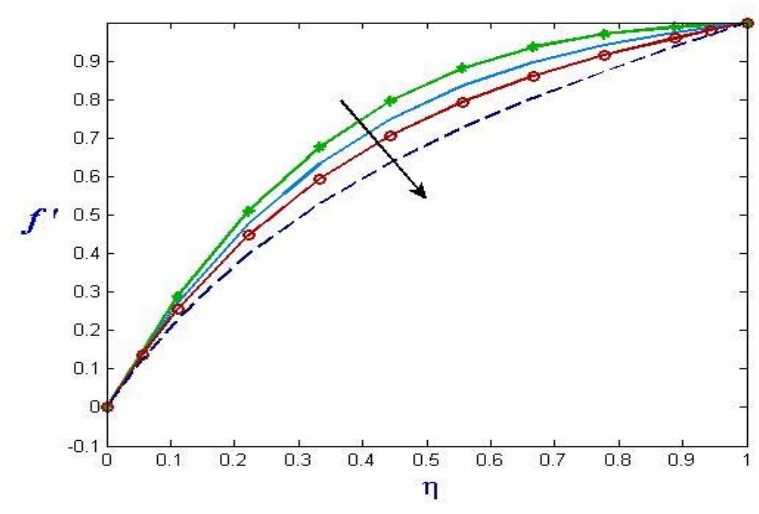

Fig.7. Velocity for different values of $\tau=1,1.5,2.0,3.0$.

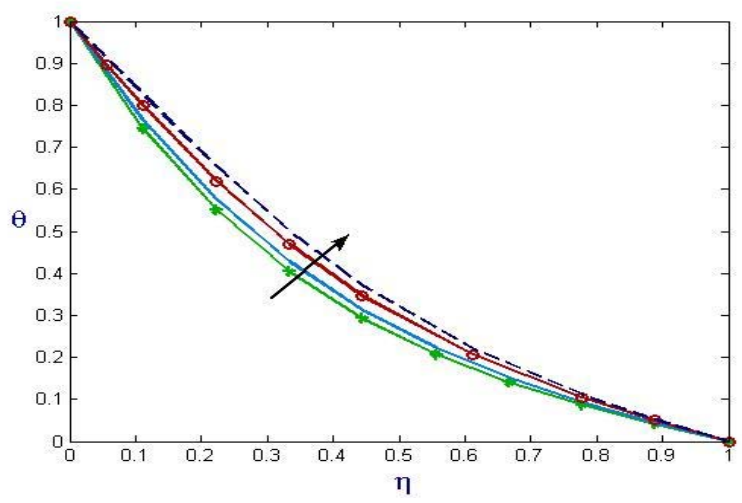

Fig.9. Temperature for different values of $E=0.05,0.15,0.30,0.40$.

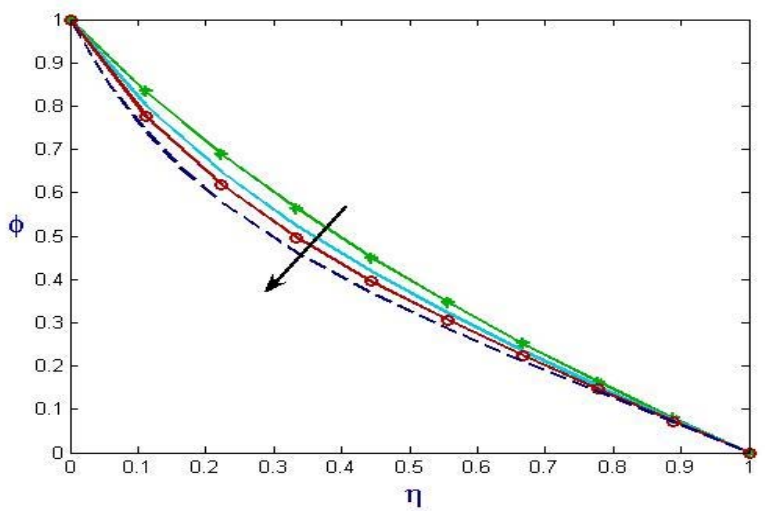

Fig.11. Concentration for different values of $S=1,2,3,4$.

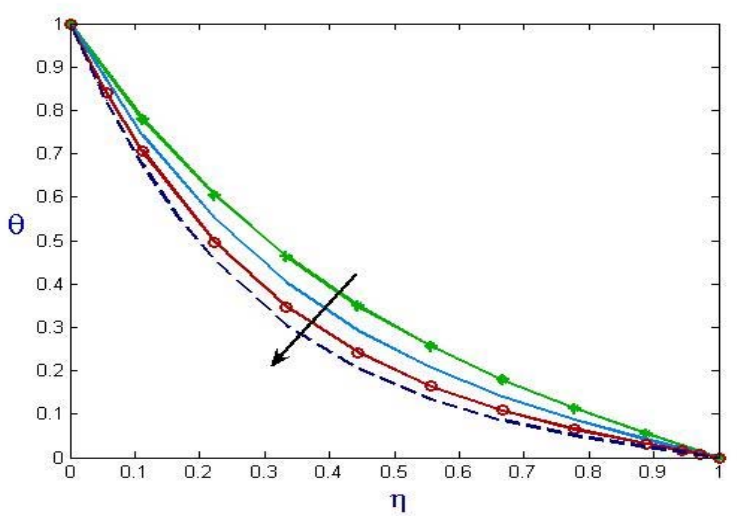

Fig.8. Temperature for different values of $P_{r}=1.7,2.5,3.5,4.5$.

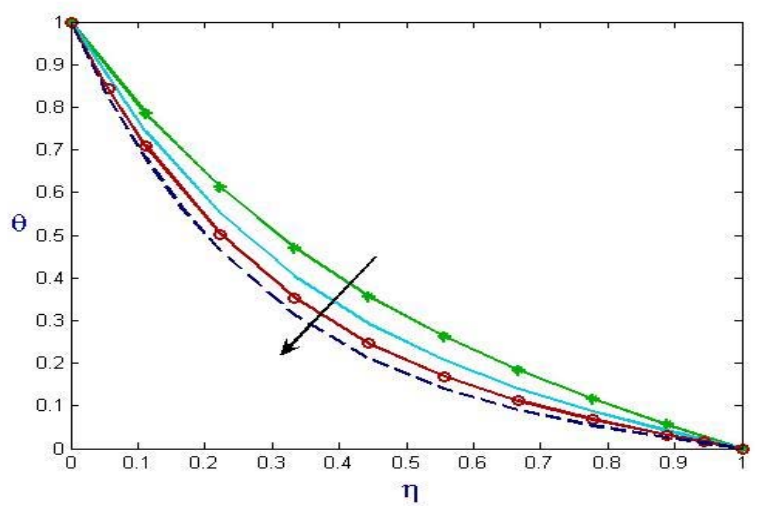

Fig.10. Temperature for different values of $S=1,2,3,4$.

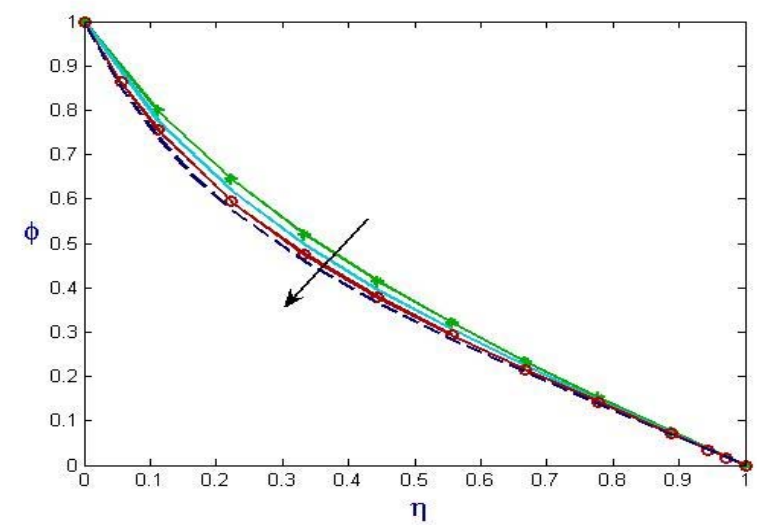

Fig.12. Concentration for different values of $P_{r}=1.7,2.5,3.5,4.5$. 


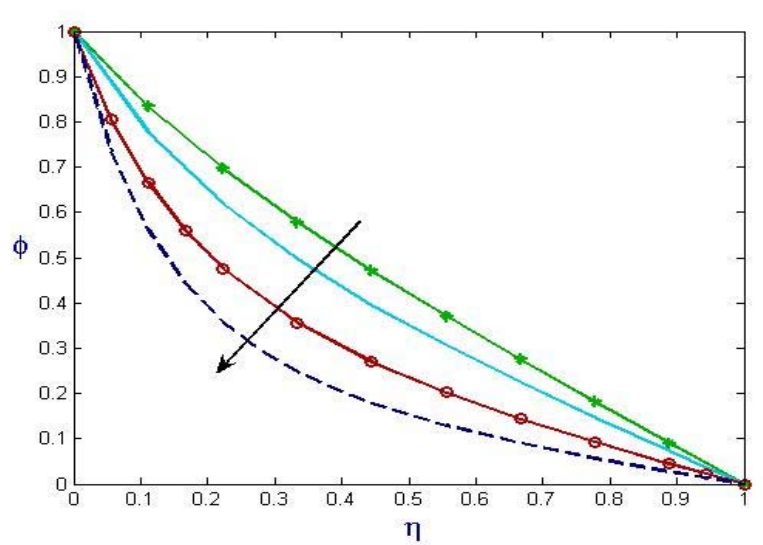

Fig.13. Concentration for different values of $S_{C}=0.25,0.5,1.0,1.5$.

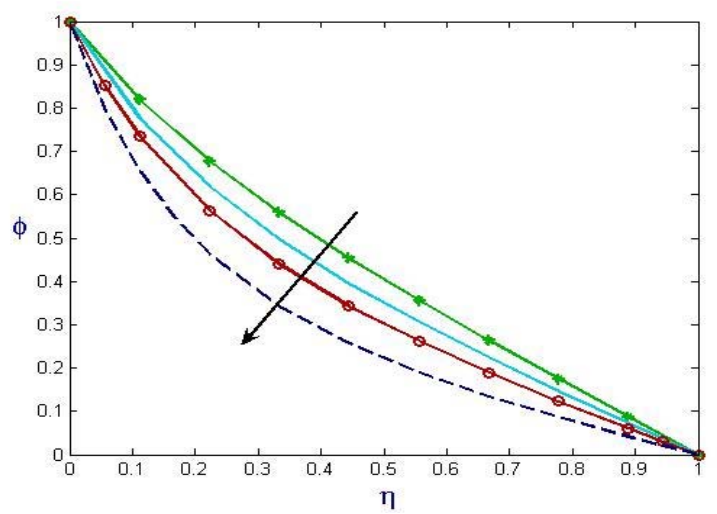

Fig.15. Concentration for different values of $\tau=1,1.5,2.0,3.0$.

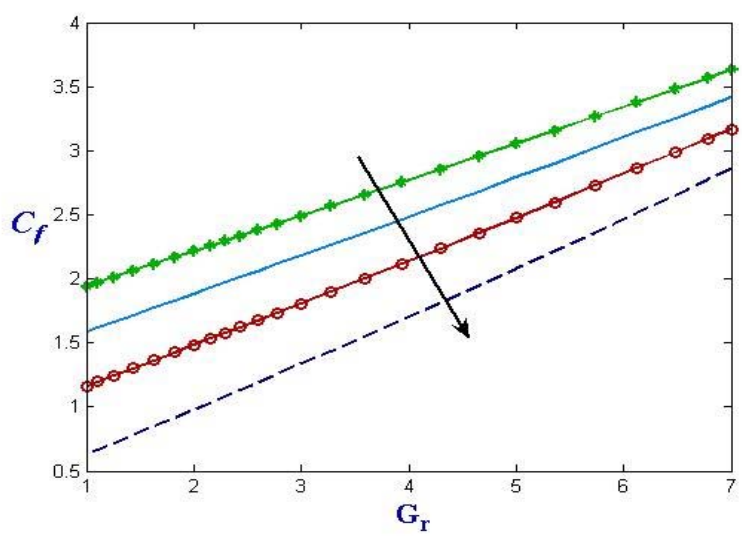

Fig.17. Skin friction for different values of $M=1,2,3,4$.

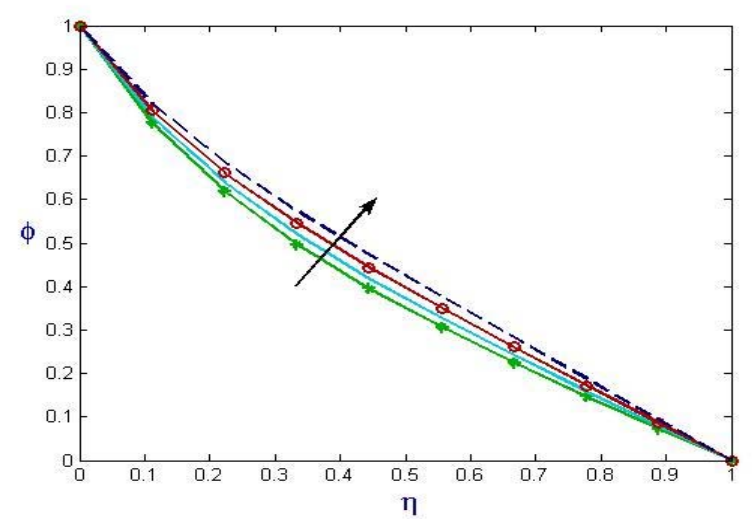

Fig.14. Concentration for different values of $\gamma=1,2,3,4$.

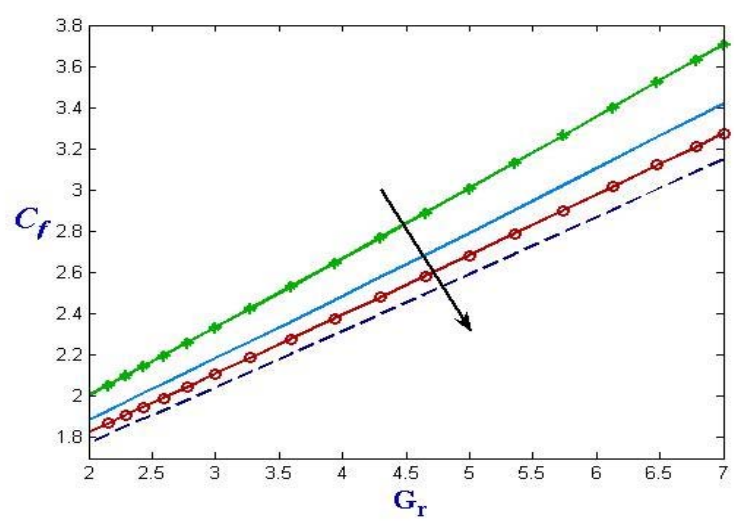

Fig.16. Skin friction for different values of $P_{r}=1.7,2.5,3.5,4.5$.

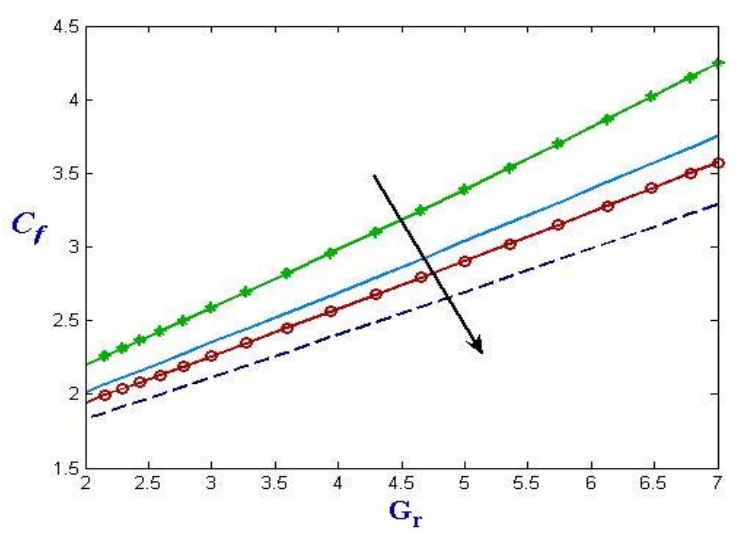

Fig.18. Skin friction for different values of $S=1,2,2.5,3.5$. 


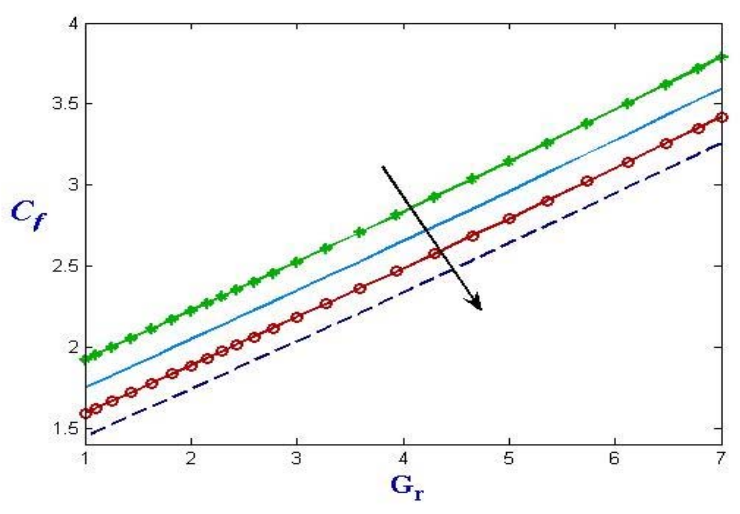

Fig.19. Skin friction for different values of $\tau=0.5,1.0,1.5,2.0$.

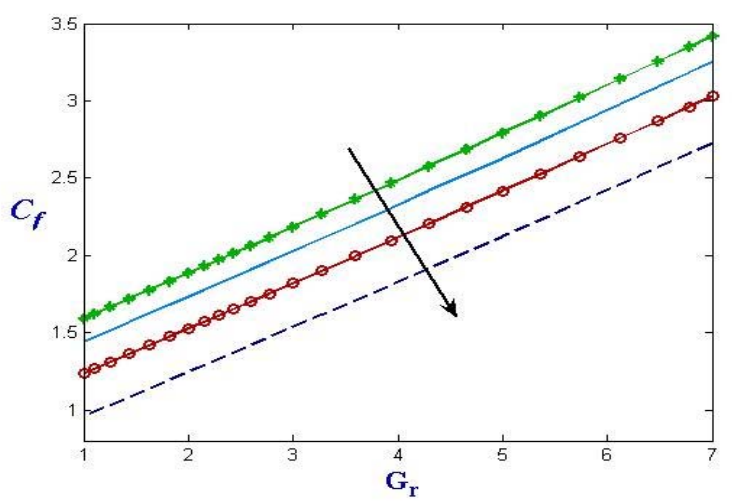

Fig.21. Skin friction for different values of $S_{C}=0.5,0.7,1.0,1.5$.

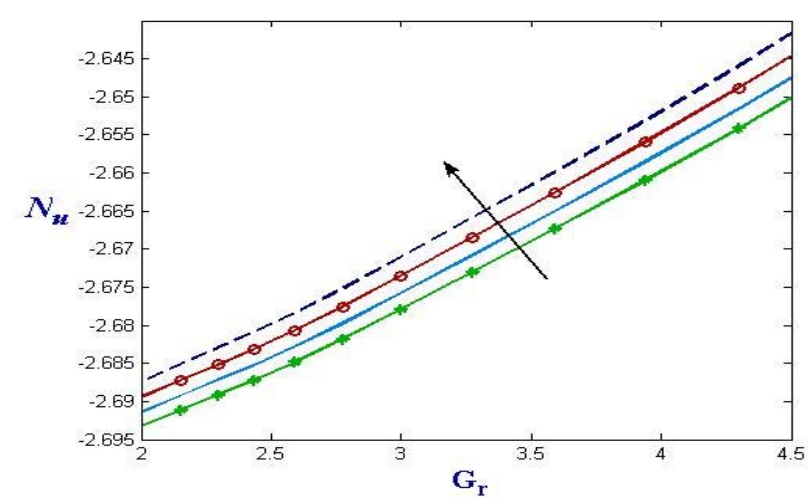

Fig.23. Nusselt number for different values of $\gamma=0.5,1.0,1.5,2.0$.

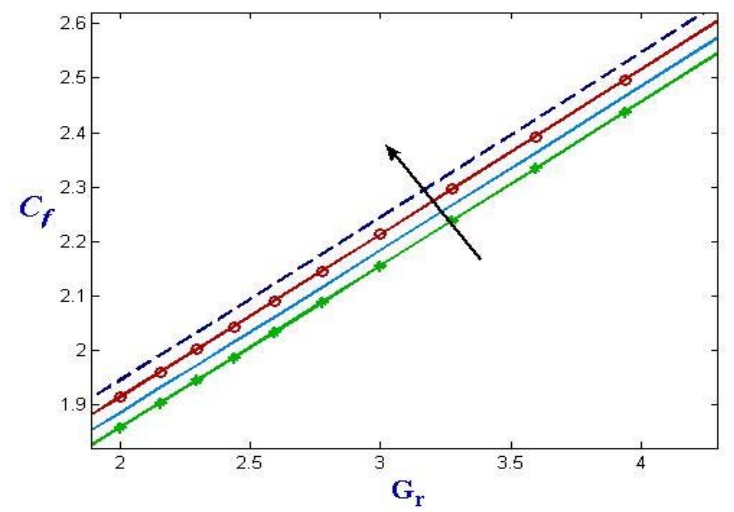

Fig.20. Skin friction for different values of $\gamma=0.5,1.0,1.5,2.0$.

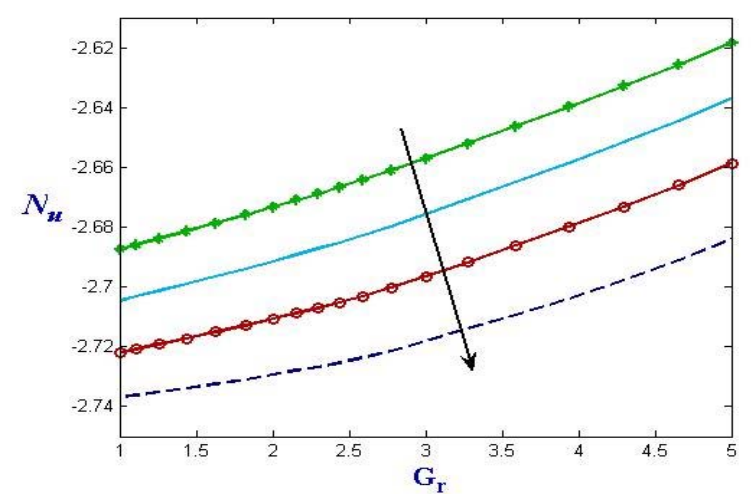

Fig.22. Nusselt number for different values of $M=1,2,3,4$.

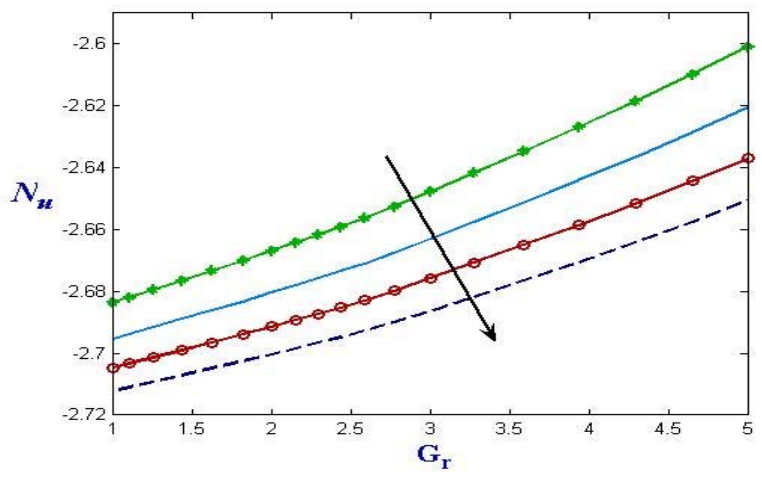

Fig.24. Nusselt number for different values of $\tau=0.5,1.0,1.5,2.0$. 


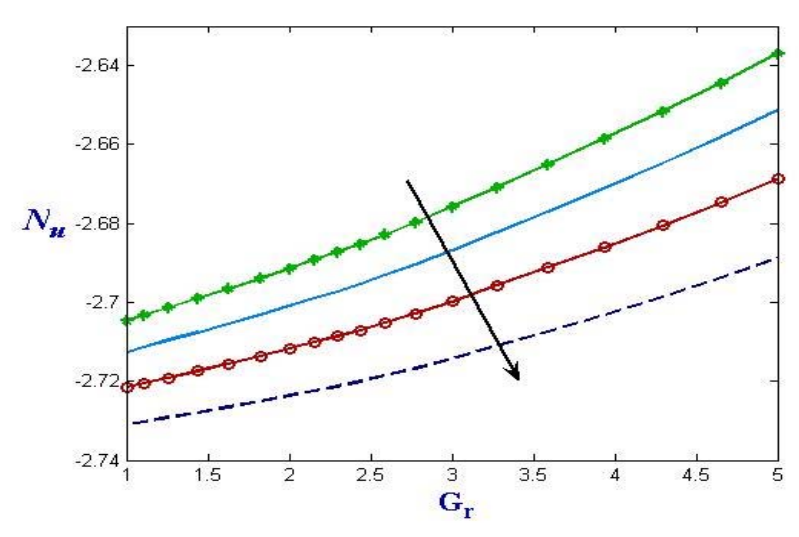

Fig.25. Nusselt number for different values of $S_{C}=0.5,0.7,1.0,1.5$.

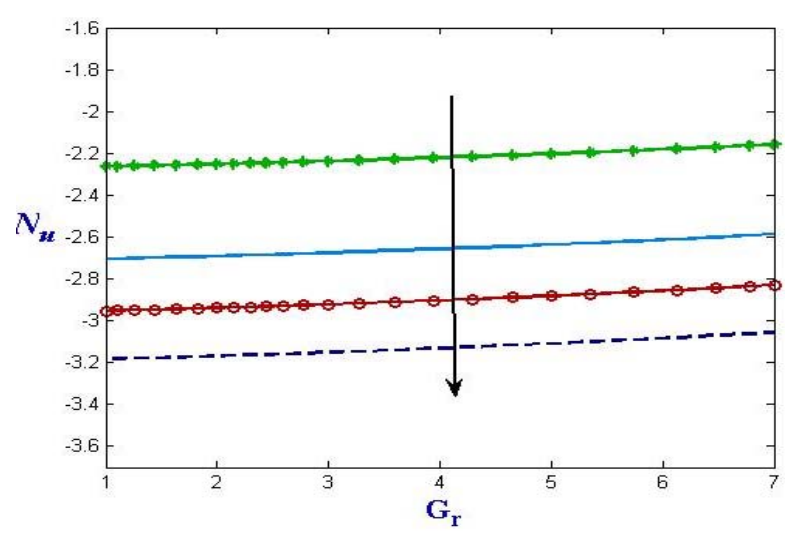

Fig.27. Nusselt number for different values of $P_{r}=1.7,2.5,3.0,3.5$.

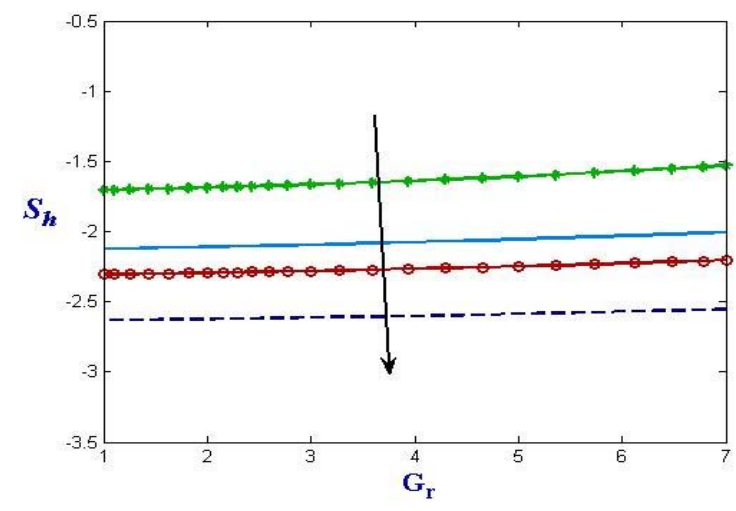

Fig.29. Sherwood number for different values of $S=1,2,2.5,3.5$.

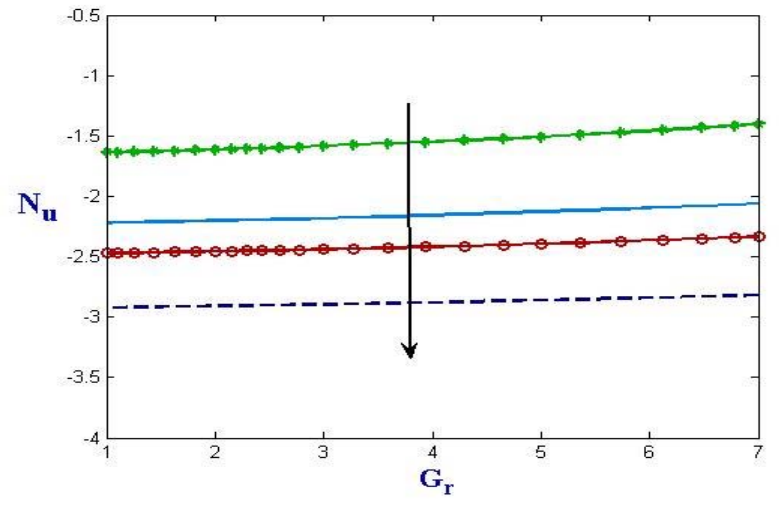

Fig.26. Nusselt number for different values of $S=1,2,2.5,3.5$.

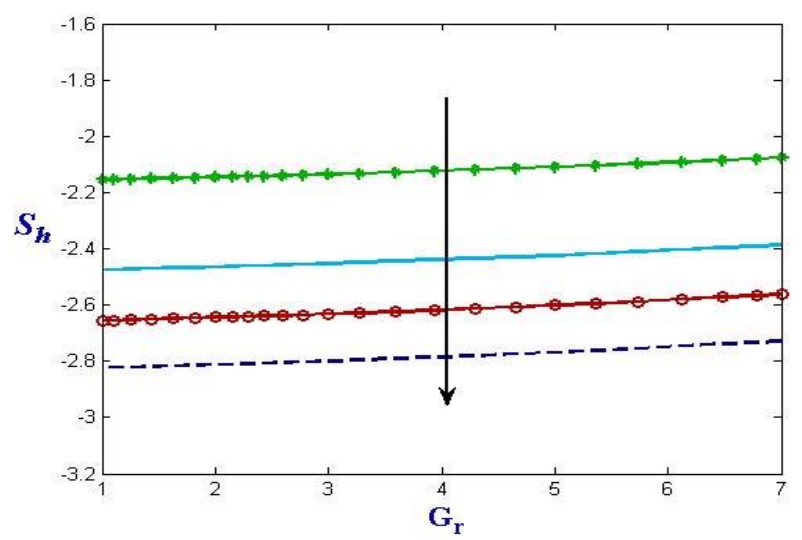

Fig.28. Sherwood number for different values of $P_{r}=1.7,2.5,3.5,4.5$.

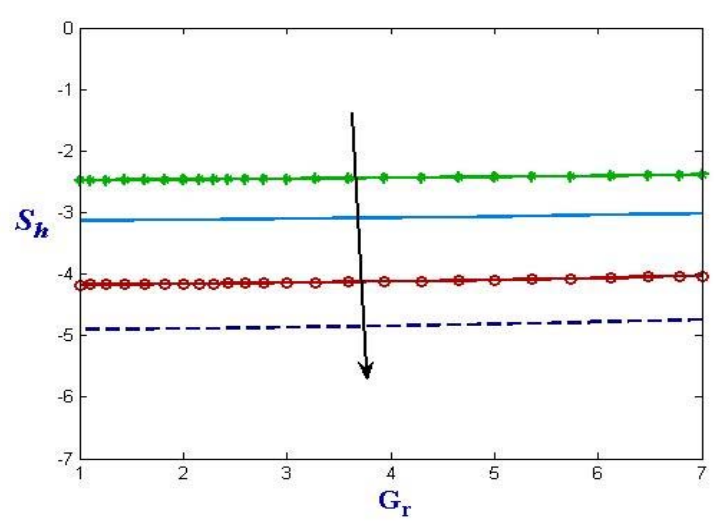

Fig.30. Sherwood number for different values of $S_{C}=0.5,0.7,1.0,1.2$. 


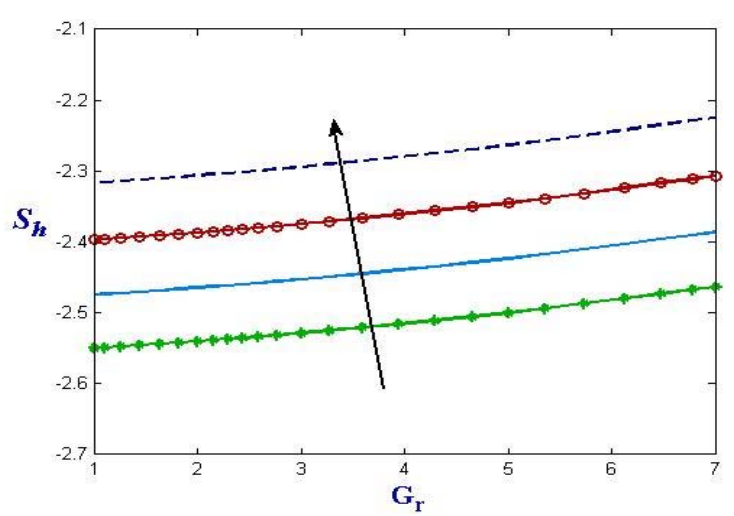

Fig.31. Sherwood number for different values of $\gamma=0.5,1.0,1.5,2.0$.

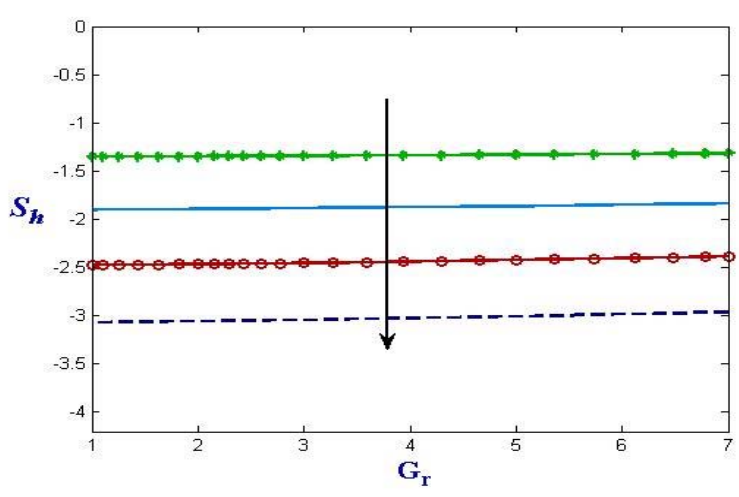

Fig.32. Sherwood number for different values of $\tau=0.5,1.0,1.5,2.0$.

\section{Conclusion}

The salient conclusions are cited below:

- the velocity and temperature fields are affected significantly by the variations of the pertinent flow parameters in the fluid flow region;

- the species concentration exhibits the diminishing trend with the growth of the Schmidt number, heat source parameter and thermophoretic parameter while a reverse nature is noticed in case of the chemical reaction parameter;

- with the acceleration of the chemical reaction parameter the skin friction gets expedited but an opposite pattern is noticed with the enhancement of other flow parameters, viz. the Prandtl number, magnetic parameter, heat source parameter and thermophoretic parameter;

- the Nusselt number and the Sherwood number get elevated with the increase of the chemical reaction parameter but show an opposite behavior in case of the magnetic parameter, Prandtl number, heat source parameter and thermophoretic parameter.

\section{Acknowledgement}

This work is supported financially by the University Grants Commission, India.

\section{Nomenclature}

$B$ - strength of the applied magnetic field

$C$ - species concentration

$C_{p}$ - specific heat at constant pressure

$C_{W}$ - species concentration at the wall

$C_{\infty} \quad$ - free stream species concentration

$D$ - coefficient of chemical molecular diffusivity

$E$ - Eckert number

$g$ - acceleration due to gravity

$G_{m}$ - solutal Grashof number

$G_{r}$ - thermal Grashof number 


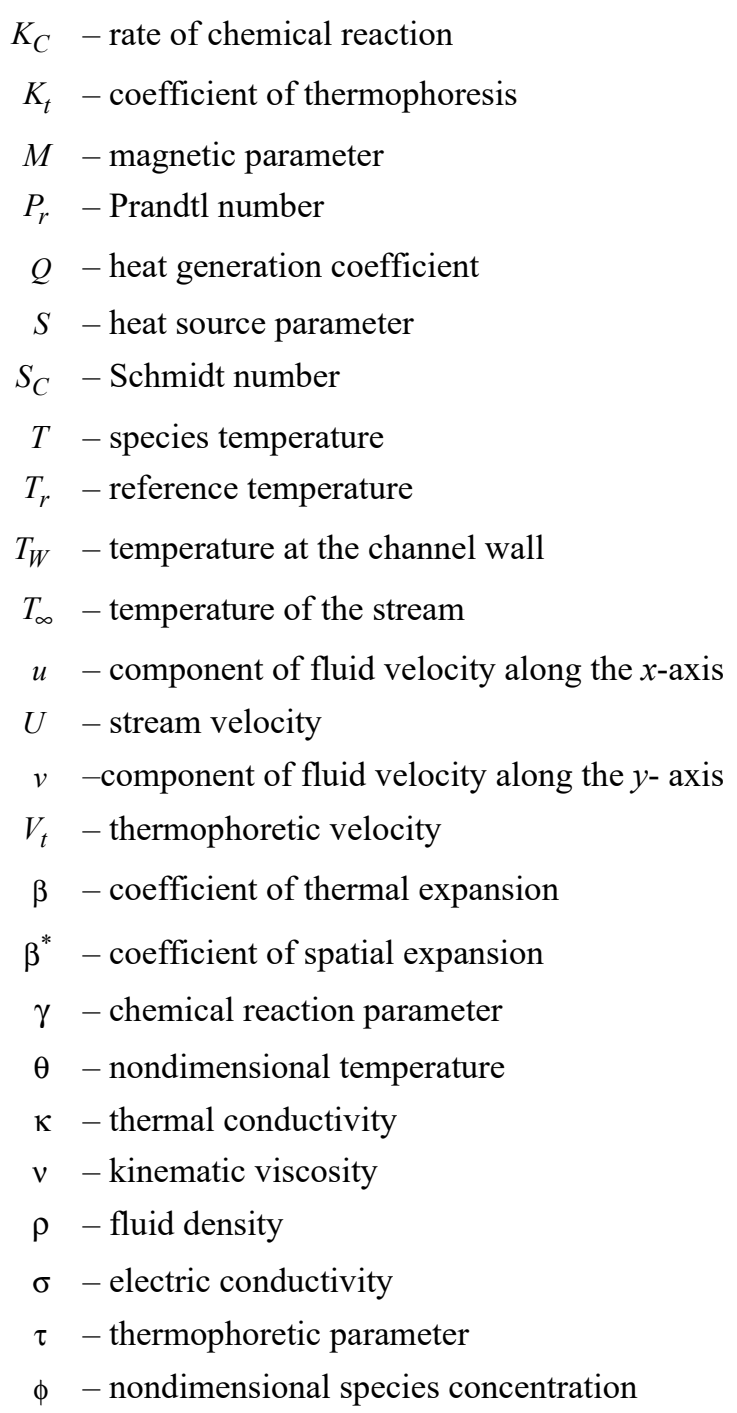

\section{References}

[1] Jeffery G. B. (1915): The two-dimensional steady motion of a viscous fluid.- Philosophical Magazine, vol.6, pp.455-465.

[2] Hamel G. (1916): Spiralförmige bewgungen zäher flüssigkeiten.- Jahresber Deutsch Math-Verein, vol.25, pp.34-60.

[3] Schlichting H. (1955): Boundary Layer Theory.- New York: McGraw-Hill.

[4] Rosenhead L. (1940): The steady two-dimensional radial flow of viscous fluid between two inclined plane walls.Proceedings of the Royal Society A, vol.175, pp.436-467.

[5] Batchelor K. (1967): An Introduction to Fluid Dynamics.- Cambridge University Press.

[6] Fraenkel L. E. (1962): Laminar flow in symmetrical channels with slightly curved walls, I. On the Jeffery-Hamel solutions for flow between plane walls.- Proceedings of the Royal Society A, vol.267, pp.119-138.

[7] Makinde O.D. and Mhone P.Y. (2006): Hermite-Pad'e approximation approach to MHD Jeffery-Hamel flows.Applied Mathematics and Computation, vol.181, No.2, pp.966-972.

[8] Hamadiche M., Scott J. and Jeandel D. (1994): Temporal stability of Jeffery-Hamel flow.- Journal of Fluid Mechanics, vol.268, pp.71-88.

[9] McAlpine A. and Drazin P. G. (1998): On the spatio-temporal development of small perturbations of Jeffery-Hamel flows.- Fluid Dynamics Research, vol.22, No.3, pp.123-138. 
[10] Asadullah M., Khan U., Ahmed N. and Manzoor R. (2013): MHD flow of Jeffery in converging and diverging channels.- International Journal of Modern Mathematical Science, vol.6, pp.92-106.

[11] Hosseini R., Poozesh S. and Dinarvand S. (2012): MHD flow of an incompressible viscous fluid through convergent or divergent channels in presence of a high magnetic field.- Journal of Applied Mathematics, vol.2012, pp.1-12.

[12] Nijsing R. and Eifler W. (1980): A computational analysis of transient heat transfer in fuel rod bundles with single phase liquid metal cooling.- Nuclear Engineering and Design, vol.62, No.1-3, pp.39-68.

[13] Bansal L. (1994): Magnetofluiddynamics of Viscous Fluids.- Jaipur: Jaipur Publishing House.

[14] Moreau R. (1990): Magnetohydrodynamics vol.3 of Fluid Mechanics and its Applications.- Dordrecht, The Netherlands: Kluwer Academic Publishers.

[15] Abel M.S., Mahesha N. and Tawade J. (2009): Heat transfer in a liquid film over an unsteady stretching surface with viscous dissipation in presence of external magnetic field.- Applied Mathematical Modelling, vol.33, No.8, pp.3430-3441.

[16] Linga Raju T. and Sreedhar S. (2009): Unsteady two-fluid flow and heat transfer of conducting fluids in channels under transverse magnetic field.- International Journal of Applied Mechanics and Engineering, vol.14, No.4, pp.1093-1114.

[17] Chandrakala P. (2013): Effects of chemical reaction on MHD flow past an impulsively started infinite vertical plate with uniform heat and mass flux.- International Journal of Applied Mechanics and Engineering, vol.18, No.2, pp.329-339.

[18] Muthucumaraswamy R. and Geetha E. (2013): Chemical reaction effects on MHD flow past a linearly accelerated vertical plate with variable temperature and mass diffusion in the presence of thermal radiation.- International Journal of Applied Mechanics and Engineering, vol.18, No.3, pp.727- 737.

[19] Zigta B. (2018): Effects of thermal radiation, chemical reaction and viscous dissipation on MHD flow.International Journal of Applied Mechanics and Engineering, vol.23, No.3, pp.787-801.

[20] Fenuga O.J., Aroloye S.J. and Popoola A.O. (2019): Analysis of chemically reactive MHD flow with heat and mass transfer over a permeable surface.- International Journal of Applied Mechanics and Engineering, vol.24, No.1, pp.53-66.

[21] Vijayalakshmi A.R. and Selvajayanthi M. (2014): Numerical study on flow past an oscillating plate with variable temperature and uniform mass diffusion under chemical reaction.- International Journal of Applied Mechanics and Engineering, vol.19, No.1, pp.181-193.

[22] Srinivasacharya D. and Jagadeeshwar P. (2019): Effect of viscous dissipation and thermophoresis on the flow over an exponentially stretching sheet.- International Journal of Applied Mechanics and Engineering, vol.24, No.2, pp.425-438.

[23] Selim A., Hossain M.A. and Rees D.A.S. (2003): The effect of surface mass transfer on mixed convection flow past a heated vertical flat permeable plate with thermophoresis.- International Journal of Thermal Sciences, vol.42, pp.973-982.

[24] Postelnicu A. (2007): Effects of thermophoresis particle deposition in free convection boundary layer from a horizontal flat plate embedded in a porous medium.- International Journal of Heat and Mass Transfer, vol.50, pp.2981-2985.

[25] Bakier A.Y. and Gorla R.S.R. (2010): Effects of thermophoresis and radiation on laminar flow along a semiinfinite vertical plate.- Heat and Mass Transfer, vol 47, pp.419-425.

[26] Noor N.F.M., Abbasbandy S. and Hashim I. (2012): Heat and mass transfer of thermophoretic MHD flow over an inclined radiate isothermal permeable surface in the presence of heat source/sink.- International Journal of Heat and Mass Transfer, vol 55,pp.2122-2128.

[27] Kundu P.K., Das K. and Jana S. (2013): Combined effects of thermophoresis and chemical reaction on magnetohydrodynamics mixed convection flow.- Journal of Thermophysics and Heat Transfer, vol.27, pp.741-747.

[28] Zueco J., Anwar Bég O., Takhar H.S. and Prasad V.R. (2009): Thermophoretic hydromagnetic dissipative heat and mass transfer with lateral mass flux, heat source, Ohmic heating and thermal conductivity effects: Network simulation numerical study.- Applied Thermal Engineering,vol.29, pp.2808-2815.

Received: December 1, 2020

Revised: April 25, 2021 